\title{
Detection of differentially expressed genes and association with clinicopathological features in laryngeal squamous cell carcinoma
}

\author{
RONG SHENG NI $^{1 *}$, XIAOHUI SHEN ${ }^{2 *}$, XIAOYUN QIAN ${ }^{2}$, CHENJIE YU $^{2}$, HAIYAN WU $^{2}$ and XIA GAO ${ }^{2}$ \\ ${ }^{1}$ Department of Otorhinolaryngology Head and Neck Surgery, BenQ Medical Center, Nanjing Medical University, \\ Nanjing 210019; ${ }^{2}$ Department of Otorhinolaryngology Head and Neck Surgery, Nanjing Drum Tower Hospital \\ Affiliated with Nanjing University School of Medicine, Nanjing 210008, P.R. China
}

Received May 7, 2012; Accepted August 3, 2012

DOI: $10.3892 / \mathrm{ol} .2012 .920$

\begin{abstract}
Head and neck cancer is a significant health problem worldwide. Early detection and prediction of prognosis will improve patient survival and quality of life. The aim of this study was to identify genes differentially expressed between laryngeal cancer and the corresponding normal tissues as potential biomarkers. A total of 36 patients with laryngeal squamous cell carcinoma were recruited. Four of these cases were randomly selected for cDNA microarray analysis of the entire genome. Using semi-quantitative RT-PCR and western blot analysis, the differential expression of genes and their protein products, respectively, between laryngeal cancer tissues and corresponding adjacent normal tissues was verified in the remaining 32 cases. The expression levels of these genes and proteins were investigated for associations with clinicopathological parameters taken from patient data. The cDNA microarray analysis identified 349 differentially expressed genes between tumor and normal tissues, 112 of which were upregulated and 237 were downregulated in tumors. Seven genes and their protein products were then selected for validation using RT-PCR and western blot analysis, respectively. The data demonstrated that the expression of SENP1, CD109, CKS2, LAMA3, ITGAV and ITGB8 was increased, while $L A M A 2$ was downregulated in laryngeal cancer compared with the corresponding normal tissues. Associations between the expression of these genes and clinicopathological data from the patients were also established, including age, tumor classification, stage, differentiation and lymph node metastasis. Our current study provides the first evidence that these seven genes may be differentially expressed in laryngeal squamous cell carcinoma and also associated with clinicopathological data.
\end{abstract}

Correspondence to: Dr Xia Gao, Department of Otorhinolaryngology Head and Neck Surgery, Nanjing Drum Tower Hospital Affiliated with Nanjing University School of Medicine, No. 321 Zhongshan Road, Nanjing City, Nanjing 210008, P.R. China E-mail:xiagao213@yahoo.com.cn

*Contributed equally

Key words: cDNA microarray, gene expression, laryngeal squamous cell carcinoma
Future study is required to further confirm whether detection of their expression can be used as biomarkers for prediction of patient survival or potential treatment targets.

\section{Introduction}

Head and neck cancer is the sixth most common type of cancer in the world, accounting for more than 540,000 new cases and 271,000 mortalities each year (1). These cancers occur in the lips, oral cavity, nasal cavity, paranasal sinuses, pharynx and larynx, $90 \%$ of which are squamous cell carcinomas. They significantly affect long-term survival and the quality of life of patients. The development of novel strategies is required for prevention and early detection, to reduce cancer incidence and overcome problems associated with treatment of late-stage tumors. Improved prediction of outcome will lead to treatment decisions that prolong patients' survival and quality of life.

Predictions concerning the outcome of head and neck cancers are currently based mostly on clinicopathological features, including tumor stage, differentiation, size and regional lymph node or distant metastasis. However, increasing numbers of studies utilize aberrant gene expression and genomic and epigenetic alterations to predict prognosis.

It has been established that tobacco smoke and alcohol consumption are the most significant risk factors for head and neck cancers. They contribute to these cancers through multiple genetic alterations, including the silencing of tumor suppressor genes and oncogene activation (2). A large body of knowledge has accumulated regarding gene alterations that are associated with the development of this deadly disease. However, greater understanding of the links between gene alteration and head and neck cancer development and progression is required.

DNA microarray profiling is an innovative technology that facilitates analysis of a great number of genes simultaneously. In this study, we performed an analysis of nearly the entire human genome in order to detect altered gene expression between primary laryngeal squamous cell carcinoma (LSCC) and adjacent normal tissues. We identified 349 genes that are differentially expressed between normal and malignant tissues, a number of which have not previously been associated with LSCC. Thus, we selected specific tumor-related genes from microarray data, which have not been reported in LSCC before. We then verified the differential expression of 
the seven genes in another set of LSCC tissues. In the future, these genes may be further evaluated as biomarkers or potential therapeutic targets for LSCC.

\section{Materials and methods}

Tissue samples. Between October 2007 and March 2010, tissue biopsy specimens (tumor and matched adjacent normal tissues) were collected from 36 patients (Table I) with LSCC at the Department of Otorhinolaryngology Head and Neck Surgery, Drum Tower Hospital Affiliated to Nanjing University School of Medicine (Nanjing, China). Pathological analyses confirmed the diagnosis of each patient. The tissues were immediately frozen in liquid nitrogen and stored at $-80^{\circ} \mathrm{C}$ until use. Our institutional Human Ethics Committee approved the study. Informed consent was obtained either from the patient or the patient's family.

RNA isolation and microarray analysis. To isolate RNA from the tissue specimens, both tumor and normal mucosae were put into liquid nitrogen and ground into powder in TRIzol reagent (Invitrogen Life Technologies, Carlsbad, CA, USA) using a rotor-stator homogenizer. Total RNA was then isolated following the manufacturer's instructions. The integrity of the RNA was verified by visual inspection after $1 \%$ agarose gel electrophoresis; the $28 \mathrm{~S}$ ribosomal RNA band intensity was two times that of the $18 \mathrm{~S}$ ribosomal RNA band (3). Sample purity was ensured by an $\mathrm{OD}_{260} / \mathrm{OD}_{280}$ ratio $>1.8$, measured with a spectrophotometer.

For DNA microarray analysis, biotinylated probes were prepared using $2 \mu \mathrm{g}$ of total RNA. Briefly, the total RNA obtained from tumor and normal tissues was mixed with $100 \mathrm{pmol}$ of T7-oligo $(\mathrm{dT})_{24}$ primer and denatured at $70^{\circ} \mathrm{C}$ for $10 \mathrm{~min}$, then chilled on ice. The first-strand cDNA synthesis was performed using Superscript II reverse transcriptase (Life Technologies, Carlsbad, CA, USA) and the second-strand with DNA Polymerase I, E. coli DNA ligase and RNase H. The biotinylated probes were then prepared from the entire cDNA reaction using an ENZO Bioarray High Yield RNA Transcript Labeling kit (ENZO Diagnostics, Toronto, Canada).

The purified probes were incubated with $1 \mathrm{X}$ fragmentation buffer at $95^{\circ} \mathrm{C}$ for 35 min to reduce the average probe length. Hybridization was performed at $45^{\circ} \mathrm{C}$ for $20 \mathrm{~h}$ with biotinylated probes on the microarrays. The non-specific binding of these probes was removed by low stringency washes (10 times) and high stringency washes (4 times) using a GeneChip Fluidics Station 400 wash station (Agilent, San Diego, CA, USA). The positive signal was detected by incubating the microarrays with streptavidin phycoerythrin (Molecular Probes, Camarillo, CA, USA) and scanned with a GeneArray Scanner (Hewlett-Packard, San Diego, CA, USA). The scanned data were analyzed with GeneChip Analysis Suite 3.3 (Agilent).

Semi-quantitative reverse transcription polymerase chain reaction (RT-PCR). To confirm the differential gene expression of laryngeal cancer revealed during cDNA microarray analysis, we used a 2-step method of semi-quantitative RT-PCR starting with tissues from 32 cases of laryngeal cancer and matched normal adjacent tissues. Briefly, total RNA was first reverse transcribed into cDNA using Superscript II reverse transcriptase (Life Technologies) and then amplified in a programmable Applied
Biosystems 2720 thermal cycler (Singapore). For each reaction, a 50- $\mu 1$ PCR mixture containing $200 \mu \mathrm{M}$ dNTPs, 1.25 units Taq polymerase in 10X Taq polymerase buffer (Takara Bio, Inc., Shiga, Japan), and corresponding concentrations of primers (Table II) was set to an initial denaturing at $95^{\circ} \mathrm{C}$ for $5 \mathrm{~min}$ and then appropriate PCR cycles for different genes of $94^{\circ} \mathrm{C}$ for $1 \mathrm{~min}$, annealing temperature (Table II) for $1 \mathrm{~min}, 72^{\circ} \mathrm{C}$ for $30 \mathrm{sec}$ and a final extension at $72^{\circ} \mathrm{C}$ for $10 \mathrm{~min}$ in a programmable 2720. The PCR reactions were performed in triplicate.

The PCR-amplified gene products were visualized in a $2 \%$ $(\mathrm{w} / \mathrm{v})$ agarose gel stained with ethidium bromide. Images of resulting gels were captured with LabWorks45 (UVP, Upland, CA, USA). The genes detected by PCR were SENP1, CD109, CKS2, LAMA2, LAMA3, ITGAV, ITGB 8 and $\beta$-actin (Table II). $\beta$-actin was used as the loading control and normalizing reference for each gene in these tissue samples. The primers were designed according to their GenBank sequences using the Primer 3 online tool.

Protein extraction and western blot analysis. Both LSCC and the matched adjacent normal tissues were homogenized for total cellular protein extraction using a commercial protein kit from Pierce Biotechnology (Rockford, IL, USA). The protein concentration of the homogenates was determined by a bicinchoninic acid protein assay kit (Shenergy Biocolor, Shanghai, China).

Equal amounts of the protein samples $(50 \mu \mathrm{g})$ were separated via $10-15 \%$ sodium dodecyl sulfate polyacrylamide gel electrophoresis (SDS-PAGE), followed by electrophoretic transfer onto polyvinylidene difluoride membranes (Roche Diagnostics, Indianapolis, IN, USA). These membranes were incubated with $5 \%$ non-fat milk in phosphate-buffered saline (PBS) for $2 \mathrm{~h}$ and then with the primary antibody at $4^{\circ} \mathrm{C}$ overnight. The primary antibodies CKS2 (\#ab54658) and SENP1 (\#ab3656) were purchased from Abcam (Cambridge, MA, USA). CD109 (\#SC33115) was obtained from Santa Cruz Biotechnology, Inc. (Santa Cruz, CA, USA). The next day, the membranes were washed with PBS 3 times and then incubated with an anti-goat or anti-rabbit horseradish peroxidase-conjugated secondary antibody (Santa Cruz Biotechnology, Inc.). The immunoreactive signals were visualized using an enhanced chemiluminescence detection kit (Pierce Biotechnology) and quantified with a densitometer (Kodak Digital Science 1D Analysis Software, Rochester, NY, USA).

Statistical analysis. DNA microarray data were analyzed using the Agilent GeneChip Analysis Suite 3.3 and summarized as fold changes. The data from semi-quantitative RT-PCR and western blot analysis were summarized as percentages of controls. The differential expression levels of genes between the tumor and normal tissues were statistically analyzed with paired-sample t-tests using SPSS 16.0 software (SPSS, Inc., Chicago, IL, USA). The association of gene expression levels with clinicopathological data was statistically analyzed with an independent-samples t-test. $\mathrm{P}<0.05$ was considered to indicate a statistically significant difference.

\section{Results}

Detection of differentially expressed genes between the primary LSCC and corresponding normal tissues. In this 
Table I. Clinical characteristics of LSCC cases studied. ${ }^{\mathrm{a}}$

\begin{tabular}{|c|c|c|c|c|c|c|}
\hline Case no. & Age (years) & Tobacco use & Alcohol use & Tumor classification & Tumor differentiation & TNM \\
\hline LSCC-001 & 71 & Yes & No & Supra-GC & $\mathrm{M}$ & T3NOMO \\
\hline LSCC-002 & 62 & Yes & No & SGC & $\mathrm{M}$ & T3NOMO \\
\hline LSCC-003 & 61 & Yes & Yes & SGC & $\mathrm{W}$ & T3NOMO \\
\hline LSCC-004 & 63 & Yes & No & $\mathrm{GC}$ & $\mathrm{W}$ & T3NOMO \\
\hline LSCC-005 & 52 & Yes & Yes & Supra-GC & M & T4NOMO \\
\hline LSCC-006 & 75 & Yes & No & Supra-GC & $\mathrm{P}$ & T3N1M0 \\
\hline LSCC-007 & 74 & Yes & No & GC & $\mathrm{W}$ & T4NOMO \\
\hline LSCC-008 & 59 & Yes & No & GC & W & T4NOMO \\
\hline LSCC-009 & 59 & Yes & Yes & $\mathrm{GC}$ & $\mathrm{P}$ & T3NOMO \\
\hline LSCC-010 & 68 & No & No & $\mathrm{GC}$ & $\mathrm{M}$ & T3NOMO \\
\hline LSCC-011 & 57 & Yes & Yes & Supra-GC & $\mathrm{W}$ & T2NOMO \\
\hline LSCC-012 & 84 & No & No & Supra-GC & $\mathrm{P}$ & T4N2M0 \\
\hline LSCC-013 & 66 & Yes & No & Supra-GC & $\mathrm{M}$ & T3NOMO \\
\hline LSCC-014 & 74 & No & No & Supra-GC & $\mathrm{M}$ & $\mathrm{T} 3 \mathrm{~N} 2 \mathrm{MO}$ \\
\hline LSCC-015 & 49 & Yes & No & Supra-GC & $\mathrm{P}$ & T3N1M0 \\
\hline LSCC-016 & 54 & Yes & Yes & GC & $\mathrm{W}$ & T3N0M0 \\
\hline LSCC-017 & 73 & No & No & Sub-GC & M & T3NOMO \\
\hline LSCC-018 & 53 & Yes & No & GC & $\mathrm{W}$ & T4NOMO \\
\hline LSCC-019 & 54 & Yes & No & Supra-GC & $\mathrm{P}$ & T4N1M0 \\
\hline LSCC-020 & 70 & Yes & No & Supra-GC & $\mathrm{P}$ & T4N2M0 \\
\hline LSCC-021 & 58 & Yes & Yes & Supra-GC & M & T4N2M0 \\
\hline LSCC-022 & 63 & Yes & Yes & Supra-GC & M & T2NOMO \\
\hline LSCC-023 & 54 & Yes & Yes & Supra-GC & M & T1N0M0 \\
\hline LSCC-024 & 60 & Yes & Yes & Supra-GC & $\mathrm{P}$ & T3N2M0 \\
\hline LSCC-025 & 53 & Yes & No & Sub-GC & M & T3NOMO \\
\hline LSCC-026 & 59 & Yes & Yes & GC & $\mathrm{W}$ & T4NOMO \\
\hline LSCC-027 & 60 & Yes & Yes & GC & $\mathrm{W}$ & T3NOMO \\
\hline LSCC-028 & 75 & Yes & Yes & Supra-GC & M & T3N1M0 \\
\hline LSCC-029 & 57 & Yes & Yes & GC & $\mathrm{W}$ & T1N0M0 \\
\hline LSCC-030 & 63 & Yes & No & GC & W & T1N0M0 \\
\hline LSCC-031 & 66 & Yes & Yes & Supra-GC & $\mathrm{W}$ & T2NOMO \\
\hline LSCC-032 & 52 & Yes & Yes & Supra-GC & $\mathrm{M}$ & T3NOMO \\
\hline LSCC-033 & 40 & Yes & No & GC & $\mathrm{M}$ & T3NOMO \\
\hline LSCC-034 & 75 & No & No & GC & $\mathrm{P}$ & T1NOMO \\
\hline LSCC-035 & 73 & Yes & Yes & $\mathrm{GC}$ & M & T1N0M0 \\
\hline LSCC-036 & 70 & Yes & Yes & $\mathrm{GC}$ & $\mathrm{M}$ & T2NOMO \\
\hline
\end{tabular}

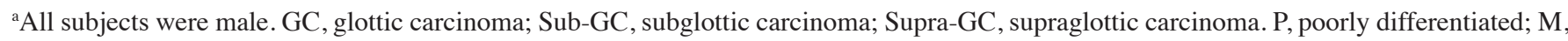
moderately differentiated; W, well-differentiated. LSCC, laryngeal squamous cell carcinoma.

study, we first randomly selected 4 pairs of primary laryngeal cancer and corresponding normal tissues for DNA microarray analysis. We then isolated RNA from the frozen tissues and performed DNA microarray analysis in Agilent chips. We identified that 10,909 genes were differentially expressed between laryngeal cancer and the matched normal tissues in case 1; 10,223 genes in case 2; 5,730 genes in case 3; and 14,665 genes in case 4 . Among these differentially expressed genes, there were 349 that were identified in all four cases, of which 112 were significantly upregulated with intensity ratios up 2.0, while 237 were downregulated with ratios down 0.5 (Table III).
Validation of microarray data using semi-quantitative RT-PCR or western blot analysis. From the microarray data we chose 7 genes whose differential status was validated with semi-quantitative RT-PCR or western blot analysis, using source material from 32 cases of laryngeal cancer and the corresponding normal tissues. The results demonstrated that expression of these 7 genes were in accordance with the microarray data (Figs. 1 and 2). Expression levels of SENP1, CD109, CKS2, LAMA3, $I T G A V$ and ITGB8 mRNA were all increased compared with the normal tissues, while LAMA2 mRNA was significant decreased in tumor tissues compared with normal tissues. As shown in Table IV, of the 32 laryngeal cancers, compared with 
Table II. Primer sequences and PCR conditions.

\begin{tabular}{|c|c|c|c|c|}
\hline Gene & Primer sequences & Annealing temperature $\left({ }^{\circ} \mathrm{C}\right)$ & No. PCR cycles & Size (bp) \\
\hline \multirow[t]{2}{*}{ SENP1 } & 5'-ACCCACCTCCTGCCACAAAC-3' & 60 & 36 & 424 \\
\hline & 5'-TTCGACGACATGAACCACTCCA-3' & & & \\
\hline \multirow[t]{2}{*}{ CD109 } & 5'-AAGCCTTTGATTTAGATGTTGC-3' & 60 & 36 & 445 \\
\hline & 5'-GAGTGATGATGGGAGCCTGA-3' & & & \\
\hline \multirow[t]{2}{*}{$C K S 2$} & 5'-CAAGCAGATCTACTACTCGG-3' & 56 & 36 & 222 \\
\hline & 5'-TGGAAGAGGTCGTCTAAAGA-3' & & & \\
\hline \multirow[t]{2}{*}{ LAMA3 } & 5'-TTCATGGGATACAGAGAGGT-3' & 58 & 36 & 446 \\
\hline & 5'-TTGGAGAAACAAGGACAGAG-3' & & & \\
\hline \multirow[t]{2}{*}{ LAMA2 } & 5'-AATTTACCTCCGCTCGCTAT-3' & 60 & 36 & 424 \\
\hline & 5'-CCTCCAATGTACTTTCCACG-3' & & & \\
\hline \multirow[t]{2}{*}{ ITGAV } & 5'-CTGGGATTGTGGAAGGAGGG-3' & 60 & 36 & 462 \\
\hline & 5'-TGCTGTAAACATTGGGGTCG-3' & & & \\
\hline \multirow[t]{2}{*}{ ITGB8 } & 5'-TGGGCCAAGGTGAAGACAAT-3' & 60 & 36 & 456 \\
\hline & 5'-ATGAGCCAAATCCAAGACGA-3' & & & \\
\hline$\beta$-actin & 5'-TCGACAACGGCTCCGGCAT-3' & 56 & 28 & 241 \\
\hline
\end{tabular}

Table III. Differentially expressed genes between primary laryngeal cancer and corresponding normal tissues.

\begin{tabular}{|c|c|c|c|c|}
\hline $\begin{array}{l}\text { GenBank } \\
\text { accession no. }\end{array}$ & Gene name & Gene symbol & $\begin{array}{l}\text { Potential } \\
\text { functions }\end{array}$ & $\begin{array}{c}\text { Fold } \\
\text { changes }\end{array}$ \\
\hline AK091217 & Amine oxidase (flavin containing) domain 1 & AOF1 & Transcription & 4.157 \\
\hline AB037807 & Ankyrin repeat and IBR domain containing 1 & ANKIBI & Signaling & 3.332 \\
\hline NM_019862 & ATP-binding cassette, sub-family C (CFTR/MRP), member 1 & $A B C C 1$ & Signaling & 3.012 \\
\hline AL834478 & CD109 antigen (Gov platelet alloantigens) & CD109 & Signaling & 3.448 \\
\hline NM_001274 & CHK1 checkpoint homolog (S.pombe) & CHEK1 & Cell cycle & 4.564 \\
\hline NM_001827 & $\mathrm{CDC} 28$ protein kinase regulatory subunit 2 & CKS2 & Cell cycle & 3.336 \\
\hline NM_018098 & Epithelial cell transforming sequence 2 oncogene & ECT2 & Signaling & 5.918 \\
\hline NM_000165 & Gap junction protein, $\alpha$ 1, $43 \mathrm{kDa}$ (connexin 43) & GJAl & Signaling & 5.305 \\
\hline NM_005329 & Hyaluronan synthase 3 & HAS3 & Metabolism & 5.493 \\
\hline NM_002210 & Integrin, $\alpha \mathrm{V}$ (vitronectin receptor) & $I T G A V$ & Adhesion & 3.778 \\
\hline ВС-002630 & Integrin, $\beta 8$ & ITGB8 & Adhesion & 5.953 \\
\hline X85108 & Laminin, $\alpha 3$ & LAMA3 & Cell structure & 2.707 \\
\hline NM_022045 & Mdm2, transformed $3 \mathrm{~T} 3$ cell double minute 2 & $M d m 2$ & Apoptosis & 4.994 \\
\hline ВC004887 & LanC lantibiotic synthetase component C-like 2 & LANCL2 & Transcription & 2.667 \\
\hline NM_014554 & SUMO1/sentrin specific protease 1 & SENP1 & Transcription & 2.688 \\
\hline AF061512 & Tumor protein p73-like & $T P 73 L / P 63$ & Cell cycle & 5.089 \\
\hline NM_000667 & Alcohol dehydrogenase 1A (class I) & $A D H 1 A$ & Metabolism & 0.109 \\
\hline NM_000669 & Alcohol dehydrogenase 1C (class I) & $A D H 1 C$ & Metabolism & 0.045 \\
\hline NM_032827 & Atonal homolog 8 (Drosophila) & АТОН & Transcription & 0.216 \\
\hline NM_006763 & BTG family, member 2 & $B T G 2$ & Transcription & 0.274 \\
\hline NM_175709 & Chromobox homolog 7 & $C B X 7$ & Transcription & 0.305 \\
\hline NM_005064 & Chemokine (C-C motif) ligand 23 & $C C L 23$ & Signaling & 0.219 \\
\hline NM_006274 & Chemokine (C-C motif) ligand 19 & CCL19 & Signaling & 0.215 \\
\hline NM_005756 & G protein-coupled receptor 64 & GPR64 & Signaling & 0.074 \\
\hline M65062 & Insulin-like growth factor binding protein 5 & IGFBP5 & Signaling & 0.253 \\
\hline L36531 & Integrin, $\alpha 8$ & ITGA8 & Adhesion & 0.395 \\
\hline NM_138284 & Interleukin $17 \mathrm{D}$ & $I L 17 D$ & Signaling & 0.123 \\
\hline NM_000426 & Laminin, $\alpha 2$ & LAMA2 & Cell structure & 0.293 \\
\hline NM_005924 & Mesenchyme homeo box 2 & MEOX2 & Transcription & 0.136 \\
\hline AK090729 & Sodium channel, voltage-gated, type II, $\beta$ & $S C N 2 B$ & Signaling & 0.163 \\
\hline NM_003256 & Tissue inhibitor of metalloproteinase 4 & TIMP4 & Growth factors & 0.2 \\
\hline
\end{tabular}




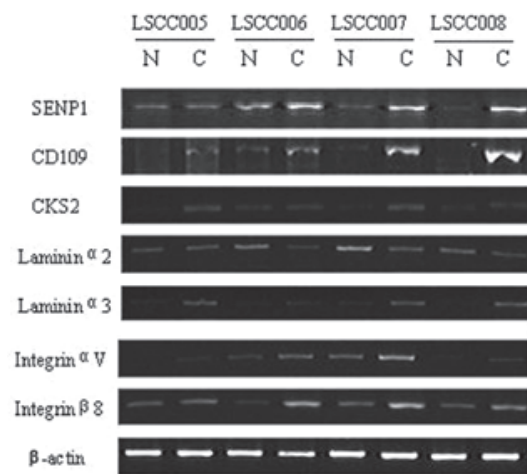

Figure 1. Semi-quantitative RT-PCR analysis of differential gene expression in 32 cases of LSCC and matched normal tissue specimens. Total RNA was isolated and subjected to RT-PCR analysis. LSCC, laryngeal squamous cell carcinoma; RT-PCR, reverse transcription polymerase chain reaction; $\mathrm{N}$, normal tissues; $\mathrm{C}$, tumor tissues.

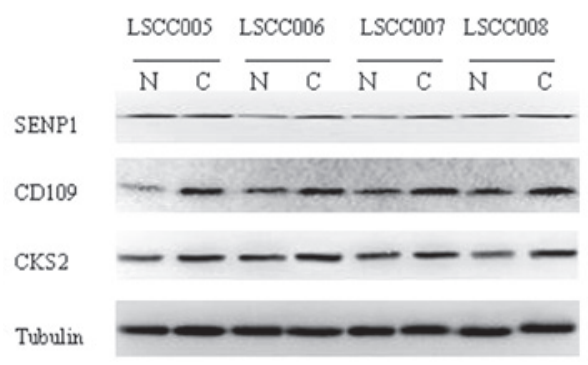

Figure 2. Western blot analysis of selected gene expression in 32 cases of LSCC and the matched normal tissue specimens. Total cellular protein was extracted and subjected to western blot analysis. LSCC, laryngeal squamous cell carcinoma; $\mathrm{N}$, normal tissues; $\mathrm{C}$, tumor tissues.

normal epithelial tissues mRNA expression of SENPI was significantly elevated in 22 cases (68.8\%), LAMA3 in 23 (71.9\%), CD109 in $26(81.3 \%), C K S 2$ in 25 (78.1\%), ITGAV in $22(68.8 \%)$ and $I T G B 8$ in $20(62.5 \%)$, while $L A M A 2$ was significantly less in $18(56.3 \%)$. Western blot data showed that of these 32 laryngeal cancer tissues, compared with the corresponding normal tissues, SENP1 protein levels were markedly higher in 21 cases (65.6\%), CD109 in 24 (75\%) and CKS2 in 23 (71.9\%; Table V).

Association of the expression of three genes with patient clinicopathological data. Statistical analysis revealed that protein levels of the three genes SENP1, CD109 and CKS2 were significantly different between tumor and corresponding normal tissues $(\mathrm{P} \leq 0.05)$. We examined their expression levels for associations with clinicopathological data, including age and tumor classification, stage, differentiation and lymph node metastasis (Table VI). SENP1 expression differed between stage I+II and III+IV tumors. CKS2 expression differed with tumor classification, tumor differentiation and lymph node metastasis. CD109 expression differed between glottic carcinoma and subglottic carcinoma.

\section{Discussion}

A profile of the genes that were differentially expressed between laryngeal cancers and corresponding normal
Table IV. Semi-quantitative RT-PCR analysis of gene expression.

\begin{tabular}{lccc}
\hline Gene & $\begin{array}{c}\text { LSCC } \\
\text { tissues }\end{array}$ & $\begin{array}{c}\text { Related adjacent } \\
\text { normal tissues }\end{array}$ & P-value \\
\hline SENP1 & $0.540 \pm 0.248$ & $0.395 \pm 0.327$ & 0.013 \\
CD109 & $0.941 \pm 0.452$ & $0.293 \pm 0.294$ & 0.000 \\
CKS2 & $13.895 \pm 4.787$ & $10.351 \pm 4.297$ & 0.000 \\
LAMA2 & $7.085 \pm 4.382$ & $11.967 \pm 7.298$ & 0.000 \\
LAMA3 & $6.276 \pm 3.922$ & $2.849 \pm 3.723$ & 0.002 \\
ITGAV & $1.013 \pm 0.478$ & $0.759 \pm 0.468$ & 0.019 \\
ITGB8 & $1.736 \pm 1.385$ & $1.227 \pm 0.936$ & 0.033 \\
\hline
\end{tabular}

RT-PCR, reverse transcription polymerase chain reaction; LSCC, laryngeal squamous cell carcinoma.

Table V. Western blot analysis of SENP1, CD109 and CKS2 protein expression in laryngeal cancer and the corresponding adjacent normal tissues.

\begin{tabular}{lccc}
\hline Protein & $\begin{array}{c}\text { LSCC } \\
\text { tissues }\end{array}$ & $\begin{array}{c}\text { Related adjacent } \\
\text { normal tissues }\end{array}$ & P-value \\
\hline SENP1 & $0.987 \pm 0.257$ & $0.775 \pm 0.237$ & 0.003 \\
CD109 & $1.827 \pm 0.676$ & $1.606 \pm 0.746$ & 0.021 \\
CKS2 & $0.827 \pm 0.389$ & $0.628 \pm 0.252$ & 0.013 \\
\hline
\end{tabular}

LSCC, laryngeal squamous cell carcinoma.

mucosae was created using cDNA microarray analysis. A total of 349 differentially expressed genes were identified in four patients, of which 112 were significantly upregulated and 237 were downregulated. We also identified certain genes that were altered in LSCC, including P63 and Mdm2. We also found other genes that were altered in human cancers, but which have not been identified before in LSCC. Thus, we selected 7 genes to study the differential mRNA and protein expression in LSCC using semi-quantitative RT-PCR and western blot analysis, respectively. The data demonstrated that, compared with the normal mucosae, 6 of the 7 genes were upregulated in laryngeal cancer and 1 was downregulated.

Associations between these genes and clinicopathological data from the patients were identified. For example, the expression of SENP1 was associated with tumor stage, while CKS2 was associated with tumor classification, differentiation and lymph node metastasis. These results imply that the detection of elevated levels of expression of SENP1 and CKS2 should be further evaluated as tumor markers for early detection or prognosis of laryngeal cancer.

The identification of genes differentially expressed between normal and malignant tissues is the first step to understanding how altered expression may contribute to tumorigenesis. These genes are likely to represent critical points of alteration in pathways that regulate the cell cycle, cell-cell adhesion and cell motility. Our current data identified a large number of genes differentially expressed in tumor tissues compared with 
Table IV. Association of SENP1, CD109 and CKS2 expression levels with patient clinicopathological data.

\begin{tabular}{|c|c|c|c|c|c|c|c|}
\hline \multirow[b]{2}{*}{ Parameter } & \multirow[b]{2}{*}{ No. } & \multicolumn{2}{|c|}{ SENP1 } & \multicolumn{2}{|c|}{ CKS2 } & \multicolumn{2}{|c|}{ CD109 } \\
\hline & & Mean \pm SD & P-value & Mean \pm SD & P-value & Mean \pm SD & P-value \\
\hline \multicolumn{8}{|l|}{ Age (years) } \\
\hline$\leq 62$ & 17 & $1.000 \pm 0.246$ & 0.793 & $0.862 \pm 0.325$ & 0.472 & $1.868 \pm 0.619$ & 0.612 \\
\hline$>62$ & 15 & $1.020 \pm 0.156$ & & $0.770 \pm 0.392$ & & $1.968 \pm 0.450$ & \\
\hline \multicolumn{8}{|c|}{ Tumor classification } \\
\hline Supra-GC & 16 & $1.012 \pm 0.154$ & $0.989^{\mathrm{a}}$ & $0.938 \pm 0.441$ & $0.040^{\mathrm{a}}$ & $1.906 \pm 0.573$ & $0.523^{\mathrm{a}}$ \\
\hline $\mathrm{GC}$ & 14 & $1.013 \pm 0.263$ & $0.792^{\mathrm{b}}$ & $0.674 \pm 0.177$ & $0.158^{\mathrm{b}}$ & $2.029 \pm 0.447$ & $0.028^{b}$ \\
\hline Sub-GC & 2 & $0.959 \pm 0.290$ & $0.678^{c}$ & $0.882 \pm 0.260$ & $0.866^{\mathrm{c}}$ & $1.187 \pm 0.524$ & $0.112^{\mathrm{c}}$ \\
\hline \multicolumn{8}{|c|}{ Tumor differentiation } \\
\hline Well & 10 & $1.030 \pm 0.257$ & $0.857^{\mathrm{d}}$ & $0.626 \pm 0.256$ & $0.068^{\mathrm{d}}$ & $1.906 \pm 0.671$ & $0.679^{d}$ \\
\hline Moderate & 14 & $1.020 \pm 0.148$ & $0.690^{\mathrm{e}}$ & $0.900 \pm 0.394$ & $0.906^{\mathrm{e}}$ & $2.004 \pm 0.353$ & $0.378^{\mathrm{e}}$ \\
\hline Poor & 8 & $0.980 \pm 0.244$ & $0.656^{\mathrm{f}}$ & $0.919 \pm 0.329$ & $0.049^{\mathrm{f}}$ & $1.770 \pm 0.665$ & $0.674^{\mathrm{f}}$ \\
\hline \multicolumn{8}{|l|}{ Tumor stage } \\
\hline $\mathrm{I}+\mathrm{II}$ & 9 & $0.920 \pm 0.102$ & 0.047 & $0.689 \pm 0.493$ & 0.212 & $2.063 \pm 0.457$ & 0.339 \\
\hline III+IV & 23 & $1.050 \pm 0.227$ & & $0.870 \pm 0.282$ & & $1.857 \pm 0.568$ & \\
\hline \multicolumn{8}{|c|}{ Lymph node metastasis } \\
\hline Yes & 9 & $1.030 \pm 0.193$ & 0.750 & $1.039 \pm 0.358$ & 0.026 & $1.935 \pm 0.504$ & 0.897 \\
\hline No & 23 & $1.000 \pm 0.214$ & & $0.733 \pm 0.322$ & & $1.907 \pm 0.564$ & \\
\hline
\end{tabular}

${ }^{\mathrm{a} C o m p a r e d ~ w i t h ~ g l o t t i c ~ c a r c i n o m a . ~}{ }^{\mathrm{b}}$ Compared with subglottic carcinoma. ${ }^{\mathrm{c} C o m p a r e d}$ with supraglottic carcinoma. ${ }^{\mathrm{d}} \mathrm{Compared}$ with moderately differentiated. ${ }^{e}$ Compared with poorly differentiated. ${ }^{\mathrm{f}}$ Compared with well-differentiated. GC, glottic carcinoma; Sub-GC, subglottic carcinoma; Supra-GC, supraglottic carcinoma.

normal tissues of the larynx. Specifically, in 4 cancer cases there were $10,909,10,223,5,730$ and 14,665 differentially expressed genes. Only 349 genes were identified to be differentially expressed in all 4 cases. These data indicate that each patient has an individualized profile with genes that may be targeted for personalized medical treatment in future studies. However, there are also genes that are commonly altered in laryngeal cancer that may be evaluated as biomarkers for early detection and prediction of prognosis of laryngeal cancer.

Of the genes whose expression is commonly elevated in laryngeal cancer, the small ubiquitin-like modifier (SUMO) is involved in numerous cellular processes, including nuclear-cytosolic transport, transcriptional regulation, apoptosis, protein stability, response to stress and progression through the cell cycle (4). The family of sentrin/SUMO-specific proteases (SENPs) is one of a group of enzymes that process newly synthesized SUMO1s into the conjugate form and catalyze the deconjugation of SUMO-containing species to regulate the function of the SUMO protein. SENP1, a member of the SENP family, has been reported to be overexpressed in colon cancer tissues (5) and has been demonstrated to regulate androgen receptor transactivation by targeting histone deacetylase I, and induce c-Jun activity through de-SUMOylation of p300 (6). Previous studies have demonstrated that SENP1 was able to transform normal prostate epithelium into a dysplasia, and also directly modulate several oncogenic pathways in prostate cells $(7,8)$. However, it remains unknown whether and how the expression of SENP1 plays a role in laryngeal cancer.

In the present study, we identified that SENPI mRNA and protein were highly expressed in laryngeal cancer tissues.
SENP1 expression was also statistically different between stage I+II and III+IV tumors. Together, these findings indicate that SENP1 may play a role in tumorigenesis and progression of laryngeal cancer.

CD109 is a glycosylphosphatidylinositol-linked glycoprotein which belongs to the $\alpha 2$ macroglobulin/C3/C4/C5 family of thioester-containing proteins. A previous study revealed that $C D 109$ was a useful diagnostic marker for basal-like breast carcinoma (9). Another study identified that CD109 may be involved in bladder tumorigenesis and might be a potential target for cancer immunotherapy (10). Zhang et al (11) detected CD109 expression in half of lung squamous cell carcinomas cases investigated, but not in lung adenocarcinomas, large cell carcinomas or small cell carcinoma. In addition, CD109 expression was found to be upregulated in approximately $50 \%$ of esophageal squamous cell carcinoma cases. In the present study, we identified that CD109 was highly expressed in laryngeal cancer tissues, and CD109 expression differed between glottic carcinoma and subglottic carcinoma. However, the number of cases of subglottic carcinoma in this study were too few to make a definitive statement; these data require confirmation with additional studies with larger sample sizes.

$C K S 2$, an essential component of cyclin/cyclin-dependent kinase complexes, contributes to cell cycle progression. Earlier studies identified $C K S 2$ as a transcriptional target that was downregulated by the tumor suppressor p53 (12). Other studies demonstrated that expression of $C K S 1$ and $C K S 2$ were elevated in prostate cancer, while knockdown of $C K S 2$ expression induced programmed cell death and inhibited tumorigenicity (13). Another study demonstrated that CKS2 
was significantly expressed in metastasized tumors (14). Using oligomicroarray analysis and qRT-PCR, Uchikado et al (15) identified $C K S 2$ as a gene associated with the lymph node metastasis of esophageal squamous cell carcinoma. The present study also revealed that CKS2 was highly expressed in laryngeal cancer and associated with tumor classification, tumor differentiation and lymph node metastasis.

Laminin, a basement membrane protein consisting of $\alpha$, $\beta$ and $\gamma$ chains, plays a critical role in the maintenance of tissue structures (16). Laminin expression is a prerequisite for normal embryonic development (17). Abnormal expression of LAMA332 and its integrin receptors is a hallmark of certain types of tumor and is considered to promote the invasion of colon, breast and skin cancer cells (18). Our present study confirmed these previous findings, although its role in laryngeal cancer requires further study.

Integrins are a group of cell adhesion molecules that regulate a wide variety of dynamic cellular processes, including cell migration, phagocytosis, growth and embryonic development. The interaction of integrins with extracellular ligands is regulated from inside the cell through the short cytoplasmic $\alpha$ - and $\beta$-integrin tails, and transmits biochemical and mechanical signals to the cytoskeleton to change cell shape, behavior and fate (19). ITGAVB6 has a role in the inhibition of colon cancer cell apoptosis through targeting the mitochondrial pathway (20). Another study (21) demonstrated that antisense ITGAV and ITGB3 inhibited tumor vascularization and growth, but enhanced the apoptosis of tumor cells. Antisense ITGAV suppressed tumor growth more markedly than antisense ITGB3. Loss of the ITGB8 subunit resulted in abnormal blood vessel development in the yolk sac, placenta and brain (22); animals lacking the ITGB8 gene die either at mid-gestation (due to insufficient vascularization of the placenta and yolk sac) or shortly after birth with severe intracerebral hemorrhage (22). Our present study also demonstrated altered expression of these integrins in laryngeal cancer.

In conclusion, our study provides the first evidence that SENP1, CD109, CKS2, LAMA2, LAMA3, ITGAV and $I T G B 8$ are differentially expressed in laryngeal cancer tissue specimens. Further study of these seven genes may aid the understanding of the multistep process of laryngeal tumorigenesis, and evaluate them as tumor biomarkers for early detection or prediction of prognosis of laryngeal cancer.

\section{Acknowledgements}

We would like to thank Dr J.D. Wu of Nanjing Medical University for his helpful advice and Mr. J.Y. Shen and Mr. L. Zhang for their technical assistance. This study was supported in part by grants from the Nanjing Technology Development Project Fund (No. 200702075), the Medical Science and Technology Development Foundation, Nanjing Department of Health (No. YKK10175), and the BenQ Medical Center Research Fund (No. SRD20100001).

\section{References}

1. Stewart BW and Kleihues P (eds): World Cancer Report International Agency for Research on Cancer, Geneva, pp232-236, 2003.
2. Mehrotra R and Yadav S: Oral squamous cell carcinoma: etiology, pathogenesis and prognostic value of genomic alterations. Indian J Cancer 43: 60-66, 2006.

3. Taylor S, Wakem M, Dijkman G, Alsarraj M and Nguyen M: A practical approach to RT-qPCR-publishing data that conform to the MIQE guidelines. Methods 50: S1-S5, 2010.

4. Hay RT: SUMO-specific proteases: a twist in the tail. Trends Cell Biol 17: 370-376, 2007.

5. Xu Y, Li J, Zuo Y, Deng J, Wang LS and Chen GQ: SUMOspecific protease 1 regulates the in vitro and in vivo growth of colon cancer cells with the upregulated expression of CDK inhibitors. Cancer Lett 309: 78-84, 2011.

6. Cheng J, Kang X,Zhang S and Yeh ET: SUMO-specific protease1 is essential for stabilization of HIFla during hypoxia. Cell 131: 584-595, 2007.

7. Bawa-Khalfe T and Yeh ET: SUMO losing balance: SUMO proteases disrupt SUMO homeostasis to facilitate cancer development and progression. Genes Cancer 1: 748-752, 2010.

8. Bawa-Khalfe T, Cheng J, Wang Z and Yeh ET: Induction of the SUMO-specific protease 1 transcription by the androgen receptor in prostate cancer cells. J Biol Chem 282: 37341-37349, 2007.

9. Hasegawa M, Moritani S, Murakumo Y, Sato T, Hagiwara S, Suzuki C, Mii S, Jijiwa M, Enomoto A, Asai N, Ichihara S and Takahashi M: CD109 expression in basal-like breast carcinoma. Pathol Int 58: 288-294, 2008.

10. Hagikura M, Murakumo Y, Hasegawa M, Jijiwa M, Hagiwara S, Mii S, Hagikura S, Matsukawa Y, Yoshino Y, Hattori R, Wakai K, Nakamura S, Gotoh M and Takahashi M: Correlation of pathological grade and tumor stage of urothelial carcinomas with CD109 expression. Pathol Int 60: 735-743, 2010.

11. Zhang JM, Hashimoto M, Kawai K, Murakumo Y, Sato T, Ichihara M, Nakamura S and Takahashi M: CD109 expression in squamous cell carcinoma of the uterine cervix. Pathol Int 55: 165-169, 2005.

12. Rother K, Dengl M, Lorenz J, Tschöp K, Kirschner R, Mössner J and Engeland K: Gene expression of cyclin-dependent kinase subunit Cks2 is repressed by the tumor suppressor p53 but not by the related proteins p63 or p73. FEBS Lett 581: 1166-1172, 2007.

13. Lan Y, Zhang Y, Wang J, Lin C, Ittmann MM and Wang F: Aberrant expression of Cks1 and Cks2 contributes to prostate tumorigenesis by promoting proliferation and inhibiting programmed cell death. Int J Cancer 123: 543-551, 2008.

14. Li M, Lin YM, Hasegawa S, Shimokawa T, Murata K, Kameyama M, Ishikawa O, Katagiri T, Tsunoda T, Nakamura Y and Furukawa Y: Genes associated with liver metastasis of colon cancer, identified by genome-wide cDNA microarray. Int J Oncol 24: 305-312, 2004.

15. Uchikado Y, Inoue H, Haraguchi N, Mimori K, Natsugoe S, Okumura H, Aikou T and Mori M: Gene expression profiling of lymph node metastasis by oligomicroarray analysis using laser microdissection in esophageal squamous cell carcinoma. Int J Oncol 29: 1337-1347, 2006.

16. Kariya Y, Mori T, Yasuda C, Watanabe N, Kaneko Y, Nakashima Y, Ogawa T and Miyazaki K: Localization of laminin alpha3B chain in vascular and epithelial basement membranes of normal human tissues and its down-regulation in skin cancers. J Mol Histol 39: 435-446, 2008.

17. Malan D, Reppel M, Dobrowolski R, Roell W, Smyth N, Hescheler J, Paulsson M, Bloch W and Fleischmann BK: Lack of laminin gammal in embryonic stem cell-derived cardiomyocytes causes inhomogeneous electrical spreading despite intact differentiation and function. Stem Cells 27: 88-99, 2009.

18. Tsuruta D, Kobayashi H, Imanishi H, Sugawara K, Ishii M and Jones JC: Laminin-332-integrin interaction: a target for cancer therapy? Curr Med Chem 15: 1968-1975, 2008.

19. Arnaout MA, Goodman SL and Xiong JP: Structure and mechanics of integrin-based cell adhesion. Curr Opin Cell Biol 19: 495-507, 2007.

20. Zhao-Yang Z, Ke-Sen X, Qing-Si H, Wei-Bo N, Jia-Yong W, Yue-Tang M, Jin-Shen W, Guo-Qiang W, Guang-Yun Y and Jun N: Signaling and regulatory mechanisms of integrin alphavbeta 6 on the apoptosis of colon cancer cells. Cancer Lett 266: 209-215, 2008.

21. Li J, Tan H, Dong X, Xu Z, Shi C, Han X, Jiang H, Krissansen GW and Sun X: Antisense integrin alphaV and beta3 gene therapy suppresses subcutaneously implanted hepatocellular carcinomas. Dig Liver Dis 39: 557-565, 2007.

22. Proctor JM,Zang K, Wang D, Wang R and Reichardt LF: Vascular development of the brain requires beta8 integrin expression in the neuroepithelium. J Neurosci 25: 9940-9948, 2005. 